\title{
PRDX1 and PRDX6 are repressed in papillary thyroid carcinomas via BRAF V600E-dependent and -independent mechanisms
}

\author{
ARIANNA NICOLUSSI $^{1 *}$, SONIA D'INZEO $^{1 *}$, GABRIELLA MINCIONE $^{4,5}$, AMELIA BUFFONE $^{2}$, \\ MARIA CARMELA DI MARCANTONIO ${ }^{4}$, ROBERTO COTELLESE ${ }^{4}$, ANNADOMENICA CICHELLA ${ }^{4}$, \\ CARLO CAPALBO $^{2}$, CIRA DI GIOIA $^{3}$, FRANCESCO NARDI $^{3}$, GIUSEPPE GIANNINI $^{2}$ and ANNA COPPA ${ }^{1}$ \\ Departments of ${ }^{1}$ Experimental Medicine, ${ }^{2}$ Molecular Medicine, ${ }^{3}$ Radiological, Oncological and Pathological Sciences, \\ Sapienza University of Rome, Rome; ${ }^{4}$ Department of Experimental and Clinical Sciences, \\ ${ }^{5}$ Center of Excellence on Aging, Ce.S.I., 'G. d'Annunzio’ University Foundation, Chieti-Pescara, Italy
}

Received September 18, 2013; Accepted November 6, 2013

DOI: $10.3892 / \mathrm{ijo} .2013 .2208$

\begin{abstract}
Many clinical studies highlight the dichotomous role of PRDXs in human cancers, where they can exhibit strong tumor-suppressive or tumor-promoting functions. Recent evidence suggests that lower expression of PRDXs correlates with cancer progression in colorectal cancer (CRC) or in esophageal squamous carcinoma. In the thyroid, increased levels of PRDX1 has been described in follicular adenomas and carcinomas, as well as in thyroiditis, while reduced levels of PRDX6 has been found in follicular adenomas. We studied the expression of PRDX1 and PRDX6, in a series of thyroid tissue samples, covering different thyroid diseases, including 13 papillary thyroid carcinomas (PTCs). Our results show that PRDX1 and PRDX6 are significantly reduced in all PTCs compared to normal tissues, to non-neoplastic tissue (MNG) or follicular neoplasms. This reduction is strongly evident in PTCs harboring BRAF V600E (31\% of our cases). Using TPC-1 and BCPAP and FRTL-5 cell lines, we demonstrate for the first time that the presence of BRAF V600E is responsible of the hypoexpression of PRDX1 and PRDX6 both at mRNA and protein levels. Finally, independently of BRAF status, we observe an interesting correlation between the tumor size, the presence of lymph node metastasis and the lowest PRDX1 and PRDX6 levels. Therefore, these data indicate that PRDX1 and PRDX6 expression not only may play a key role in papillary thyroid carcinogenesis via a BRAF V600E-dependent mechanism, but their determination could be considered as potential tumor marker for indicating tumor progression in PTCs, independently of BRAF status.
\end{abstract}

Correspondence to: Dr Anna Coppa, Department of Experimental Medicine, Sapienza University of Rome, v. le R. Elena 324, I-00161 Rome, Italy

E-mail: anna.coppa@uniroma1.it

*Contributed equally

Key words: PRDX1, PRDX6, BRAF V600E, papillary thyroid carcinomas

\section{Introduction}

In recent years, several studies have linked oxidative stress (OS) to thyroid cancer (1-3). The thyroid gland itself generates reactive radical molecules, through the process of iodine metabolism and thyroid hormone synthesis. During this process, TSH stimulates $\mathrm{H}_{2} \mathrm{O}_{2}$ production, which is the substrate of thyroperoxidase (TPO) on the apical membrane of the thyroid follicular cells (4). Therefore, thyrocytes need protective mechanisms that limit the oxidative damage of $\mathrm{H}_{2} \mathrm{O}_{2}$ production by catalase, gluthatione peroxidases and peroxiredoxins (PRDXs) $(4,5)$. PRDX proteins belong to a highly conserved family of six proteins. All of the PRDXs contain a conserved cysteine residue in the $\mathrm{N}$-terminal region, that is the active site that catalyzes peroxide reduction of $\mathrm{H}_{2} \mathrm{O}_{2}(6)$. These proteins can be classified in 2-cysteine (2-Cys) PRDXs including PRDX1-5, and 1-Cys PRDX including PRDX6. Together with their cytoprotective antioxidant function, PRDXs play a role in cell proliferation, differentiation, immune response, protection of oxidation-sensitive proteins, regulation of cellular $\mathrm{H}_{2} \mathrm{O}_{2}$, control of apoptosis and redox signaling (7). PRDX1 is the most abundant and ubiquitously distributed member of the mammalian PRDX family, identified in a large variety of organisms, while PRDX6 is the only 1-Cys PRDX that has glutathione peroxidase and phospholipase A2 (PLA2) activities (8). Their function has been mainly related to regulating cell proliferation, differentiation, and apoptosis $(9,10)$. Data obtained in cells and in mice lacking PRDX1 indicate that it exerts a strong tumor suppressor function (11), interacting with c-Myc and selectively inhibiting its transcriptional activity (12). On the other hand, because of their antioxidant function, PRDXs may support tumor survival and maintenance, by protecting tumor cells from oxidative stress-induced apoptosis (13). Many clinical studies highlight this dichotomous role of PRDXs in various kinds of human cancers. Increased or reduced level of PRDX1 was described in lung and breast cancer (14-17), as well as in aggressive esophageal squamous carcinomas (18). Aberrant expression of PRDX6 has been reported in a variety of tumors such as malignant mesothelioma (19), esophageal carcinoma (20), oligodendroglioma (21), breast cancer (22) and squamous cell carcinomas (23). 
Studies on the role of PRDXs in thyroid diseases demonstrated modification in the expression of these proteins mainly in follicular neoplasms. Increased level of PRDX1 has been described in follicular adenomas and carcinomas, as well as in thyroiditis (24). Recently, thyroid proteomic approach highlighted a reduction of PRDX6 in follicular adenomas (25), suggesting a possible role for this protein as complementary marker to distinguish between different follicular neoplasms. Based upon this knowledge, we studied the expression of two representative members of PRDXs family, PRDX1 and PRDX6, in a group of 32 thyroid tissue samples covering different thyroid diseases, including 13 papillary thyroid carcinomas (PTCs). PTC accounts for $80-90 \%$ of all thyroid cancers $(26,27)$. Although the majority of these cancers, treated with surgical thyroidectomy, followed by radioiodine ablation in many patients, have an excellent prognosis, there are $20-30 \%$ of cases that show recurrence at $15-20$ years $(28,29)$. At least $45 \%$ of PTCs with worst prognosis harbor the oncogenic BRAF V600E mutation, which leads to a constitutive activation of the $\mathrm{RAF} / \mathrm{MEK} / \mathrm{ERK}$ pathway. PTCs with this BRAF mutation behave more aggressively than wild-type BRAF (WT) tumors, and their clinical outcome correlates to extrathyroidal extension, positive nodal status, disease recurrences, and mortality (30-32). Our data show that PRDX1 and PRDX6 levels are strongly reduced in all PTCs compared not only to normal tissue (NT), but also to non-neoplastic tissue or follicular neoplasms (FA and FC). We demonstrate for the first time that PRDXs reduction correlates with the presence of BRAF V600E mutation both in human samples and in papillary thyroid carcinoma cellular model. The significant reduction of PRDX1 and PRDX6 obtained in FRTL-5 cells, transiently transfected with of BRAF V600E, allowed us to state that these molecules are a new target of BRAF V600E. Finally, independently of BRAF status, we observed an interesting correlation between tumor size, the presence of lymph node metastasis and the lowest PRDX1 and PRDX6 levels. Therefore, these data indicate that PRDX1 and PRDX6 reduction may play a key role in pathogenesis of papillary thyroid cancer and they could be considered as potential tumor markers for indicating tumor progression in PTCs.

\section{Materials and methods}

Tumor samples. Thirty-two tissue samples of different histological subtype, collected between 2005 and 2011 in the Department of Experimental and Clinical Sciences University 'G. d'Annunzio' Chieti-Pescara, frozen immediately in liquid nitrogen and stored at $-80^{\circ} \mathrm{C}$, were analyzed by qRT-PCR to evaluate the expression levels of PRDX1 and PRDX6 genes. In all cases, the contralateral normal thyroid tissue was simultaneously processed in a similar manner. Sample collection includes: 13 cases of PTC (10 females, 3 males; median age $52.85 \pm 15.10$ years; median \pm SD), 13 follicular adenomas (FA) (10 females, 3 males; median age $44.92 \pm 17.33$ years), 3 multinodular goiter (MNG) (3 females; median age $44 \pm 8.19$ years), and 3 follicular carcinomas (FC) ( 2 females, 1 male; median age $40.33 \pm 22.90$ years). The clinical and histological features, including the TNM staging, are shown in Table I. Samples of normal thyroid tissue were obtained from healthy contralateral lobe of each of patient.
Table I. Clinical and histopathological features of the study population.

\begin{tabular}{|c|c|c|}
\hline & \multicolumn{2}{|c|}{ Benign nodule $(n=16)$} \\
\hline & $\begin{array}{l}\text { Multinodular } \\
\text { goiter (MNG) }\end{array}$ & $\begin{array}{c}\text { Follicular } \\
\text { adenoma (FA) }\end{array}$ \\
\hline No. of patients & 3 & 13 \\
\hline \multicolumn{3}{|l|}{ Gender } \\
\hline Female/male & $3 / 0$ & $10 / 3$ \\
\hline \multirow[t]{3}{*}{ Median age } & $44 \pm 8.19$ & $44.92 \pm 17.33$ \\
\hline & \multicolumn{2}{|c|}{ Malignant nodule $(n=16)$} \\
\hline & $\begin{array}{l}\text { Papillary thyroid } \\
\text { carcinoma (PTC) }\end{array}$ & $\begin{array}{c}\text { Follicular } \\
\text { carcinoma }(\mathrm{FC})\end{array}$ \\
\hline No. of patients & 13 & 3 \\
\hline \multicolumn{3}{|l|}{ Gender } \\
\hline Female/male & $10 / 3$ & $2 / 1$ \\
\hline Median age & $52.85 \pm 15.10$ & $40.33 \pm 22.90$ \\
\hline \multicolumn{3}{|l|}{ TNM no. (\%) } \\
\hline $\mathrm{T}_{1} \mathrm{~N}_{\mathrm{x}}$ & $4(30.8)$ & \\
\hline $\mathrm{T}_{2} \mathrm{~N}_{\mathrm{x}}$ & & $3(100)$ \\
\hline $\mathrm{T}_{1} \mathrm{~N}_{0}$ & $3(23.1)$ & \\
\hline $\mathrm{T}_{2} \mathrm{~N}_{0}$ & $2(15.4)$ & \\
\hline $\mathrm{T}_{1} \mathrm{~N}_{1}$ & $2(15.4)$ & \\
\hline $\mathrm{T}_{2} \mathrm{~N}_{1}$ & $2(15.4)$ & \\
\hline
\end{tabular}

For the IHC study, the same formalin-fixed, paraffinembedded cases were analyzed to evaluate the expression levels of PRDX1 and PRDX6 proteins. Informed consent from individual patients was not necessary because all data were made anonymous. This investigation was performed according to the guidelines of the Ethics Committee of the University Hospital Essen and in accordance with the precepts established by the Helsinki declaration. Histopathology evaluation and TNM classification were performed by two expert thyroid pathologists (R.C. and C.D.G.).

Immunohistochemistry. Immunohistochemistry was performed, as described in Lazzereschi et al (33), on formalin-fixed, paraffin-embedded tissue sections of thyroid tumors from 13 patients. Consecutive histological sections $(2 \mu \mathrm{m})$, mounted on slides coated with a suitable tissue adhesive, were deparaffinized in xylene and rehydrated through graded alcohol series. Endogenous peroxidase was blocked by $3 \%$ hydrogen peroxide/ methanol for $10 \mathrm{~min}$. Sections were placed in blocking serum (UCS Diagnostic, Morlupo, Rome, Italy) for $10 \mathrm{~min}$ and then were incubated, at room temperature for $1 \mathrm{~h}$, with primary antibody: rabbit polyclonal anti-human PRDX1 (1:400) or mouse monoclonal anti-human PRDX6 (1:400) (Abcam, Cambridge, MA, USA). After incubation, tissue sections were washed with PBS buffer and incubated with the appropriate biotinylated secondary antibody for $15 \mathrm{~min}$ at room temperature and then with streptavidin/peroxidase complex (UltraTek HRP Ready- 


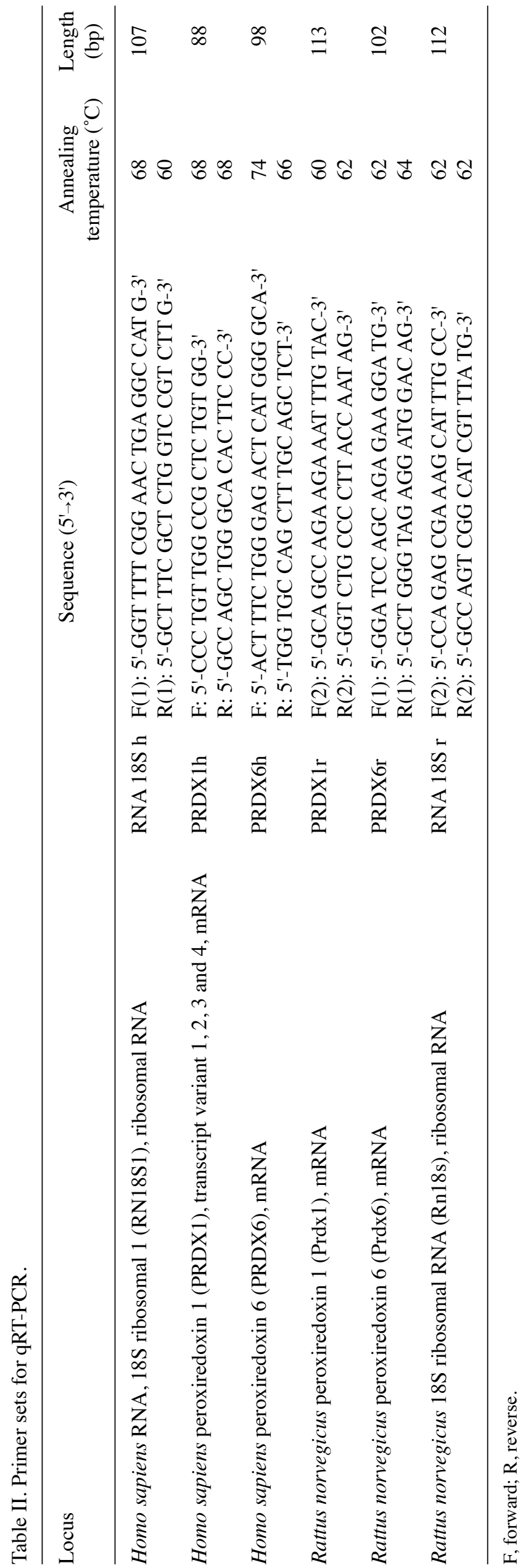

to-use, UCS Diagnostic) for $15 \mathrm{~min}$ at room temperature. Tissues were then developed in 3',3'-diaminobenzidine (DAB, Dako, CA, USA), resulting in a brown reaction product. The slides were subsequently counterstained with hematoxylin.

Thyroid tissue with histological diagnosis of Graves' disease were used as positive control. Negative controls were obtained omitting the primary antibodies. Two investigators examined the slides in a blinded manner by a Leica microscope (Leitz Camera, Wetzlar, Germany) using normal light. The evaluations of the two pathologists were $100 \%$ concordant.

RNA isolation and analysis. Total RNA from tissue and cells was extracted using TRI Reagent (Sigma-Aldrich, Co.), following the manufacturer's instructions. Using $1 \mu \mathrm{g}$ RNA, cDNAs were synthesized using MuLV reverse transcriptase (Applied Biosystems, Hammonton, NJ, USA) and random primers (Roche) according to the manufacturer's instructions. Real-time reverse transcription (RT)-PCR was performed three times in six replicates on ABI PRISM 7900HT (Applied Biosystems, Foster City, CA), using the SYBR Green detection system. mRNA levels were compared with reference curves and normalized to $18 \mathrm{~S}$ ribosomal RNA. Each experiment was repeated three times using different total RNA extracts. The primers used in qRT-PCR and relative parameters are reported in Table II.

For analysis of the BRAF gene mutation, exon 15 of BRAF was amplified using the polymerase chain reaction (PCR) with the following primers: BRAF $h \mathrm{~F}(1)$ : 5'-CGA CAG ACT GCA CAG GGC A-3' and BRAF h R(1): 5'-GCC ATC CAC AAA ATG GAT CCA-3' (62 ${ }^{\circ} \mathrm{C}$; amplicon of $\left.191 \mathrm{bp}\right)$.

Amplification products were analyzed using a $2 \%$ agarose gel and purified with ExoSap-IT (USB Corporation). Nucleotide sequence analysis was performed using the BigDye Terminator v1.1 Cycle Sequencing Kit (Applied Biosystems). The purified PCR products were sequenced in both directions using BRAF $h$ $\mathrm{F}(1)$ and $\mathrm{BRAF} h \mathrm{R}(1)$ primers. Cycle sequencing products were analyzed using the ABI PRISM 310 Genetic Analyzer (Applied Biosystems, Darmstadt, Germany).

Cell cultures and transient transfection analysis. For the present study, FRTL-5 cells were obtained from the American Type Culture Collection (ATCC), Rockville, MD. They were designated as ATCC CRL 8305 and described as passage 14. On arrival, they were divided into aliquots and frozen in liquid nitrogen until required.

FRTL-5 cell line, diploid between their 5th and 25th passage, maintains the functional characteristics of iodide uptake, thyroglobulin synthesis, and cyclic nucleotide metabolism over prolonged periods of culture and doubling time of $36 \mathrm{~h}$ (34). The cells were grown as previously described (35) at $37^{\circ} \mathrm{C}$ in a humidified atmosphere of $5 \% \mathrm{CO}_{2}$ air in w/o supplemented with $5 \%$ calf serum and $6 \mathrm{H}$ mixture. FRTL- 5 were transiently transfected with pBABE BRAF V600E plasmid (kindly provided by Professor G. Canettieri) using lipofectin technique following the manufacturer's instructions. After $48 \mathrm{~h}$ of incubation, transfected cells were used in qRT-PCR and western blot assays.

The human PTC cell lines, TPC-1 (BRAF WT/WT) and BCPAP (BRAF V600E/V600E), characterized according to Schweppe et al (36), were maintained in a $5 \% \mathrm{CO}_{2}$ culture humidified atmosphere, at $37^{\circ} \mathrm{C}$ in DMEM supplemented with $10 \%$ calf serum (37). 


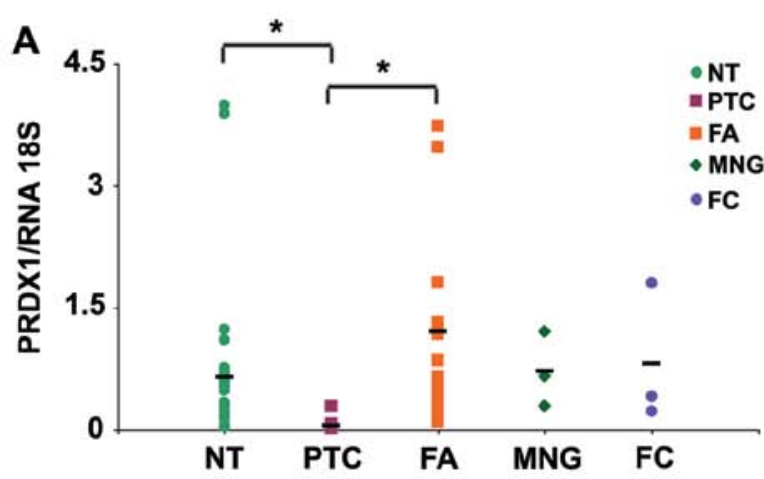

$\mathbf{B}$

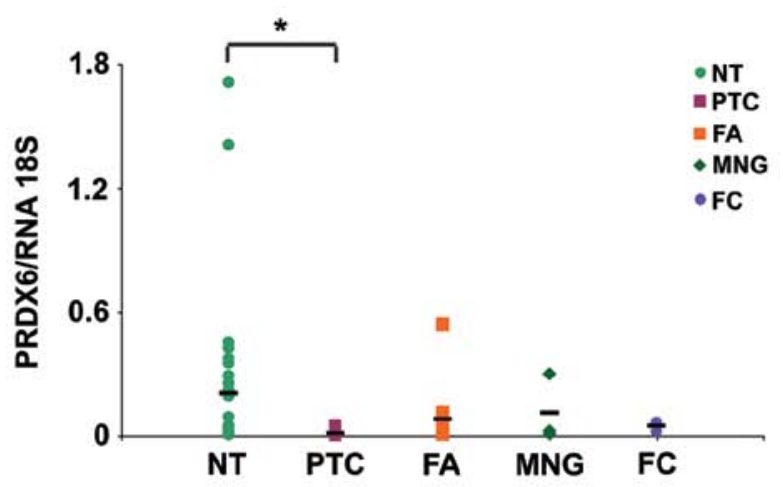

C

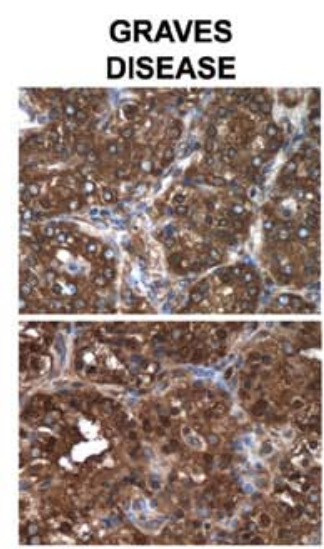

Figure 1. PRDX1 and PRDX6 expression in thyroid diseases. (A) Relative gene expression levels of PRDX1 and PRDX6 normalized to 18S RNA in normal and tumor thyroid tissues were determined using gene-specific primers as described in Materials and methods. Values represent mean of triplicate determination \pm SD of three experiments. "Statistical significance (Student's t-test, P<0.05) of PTC vs normal tissue or vs FA. (B) Representative PRDX1 and PRDX6 immunohistochemistry (original magnification, x400) of a PTC and non-neoplastic thyroid sample. (C) Tissues from thyroid Graves' disease were introduced as positive controls.

Protein extraction and immunoblotting. Protein extracts from subconfluent cells, transfected or not, were obtained using icecold TNE extraction buffer (50 mM Tris- $\mathrm{HCl}$ pH 7.8, $150 \mathrm{mM}$ $\mathrm{NaCl}, 1 \mathrm{mM}$ EDTA, and 1\% Triton X-100) supplemented with $1 \mathrm{mM}$ PMSF, protease and phosphatase cocktail inhibitors. Protein lysates $(50 \mu \mathrm{g})$ were subjected to immunoblotting as previously described (38), using primary antibodies to PRDX1 (1:1000) (Abcam), PRDX6 (1:1000) (Abcam), CREB (Cell Signaling Technology, Beverly, MA, USA) (1:1000).

Then the membranes were incubated with anti-rabbit (1:50000) or anti-mouse (1:10000) HRP-conjugated secondary antibodies (Sigma-Aldrich Co.). The western blots were revealed by chemiluminescence using the Super Signal Kit from Pierce (Rockford, IL, USA), according to the manufacturer's instructions and visualized on CL-Xposure film (Pierce).

PRDX1 and PRDX6 bands were analyzed using Bio-Rad Laboratories software. Data, obtained from three different protein extracts, were collected in terms of average intensity of bands of each proteins per average intensity of bands of CREB.

Statistical analysis. All statistical analyses have been performed by JMP Software, purchased from Statistical Discovery SAS Institute (Cary, NC, USA). Data were analyzed by Student's t-test $(\mathrm{P}<0.05$, statistical significance; $\mathrm{P}<0.001$, high statistical significance; $\mathrm{P}<0.0001$, very high statistical significance).

\section{Results}

Peroxiredoxin 1 and peroxiredoxin 6 are reduced in PTCs. The expression of PRDX1 and PRDX6 was evaluated by qRT-PCR in a series of 32 snap-frozen thyroid samples (Table I), including 13 PTC, 3 FC, 13 FA, 3 MNG and, in all cases, in normal thyroid tissue samples from the contralateral lobe. All examined tissues showed detectable levels of PRDX1 and PRDX6. The comparative analyses of the groups demonstrated higher value of $P R D X 1$ in follicular neoplasm FA and in FC as compared to normal tissue ( $\sim 2$ - and 1.3-fold respectively) or to non-neoplastic tissue MNG ( 1.7- and 1-fold respectively). The PRDX6 levels are moderately decreased in FA and in FC compared to NT ( 2.5- and 4-fold respectively) and to MNG ( 1.4- and 2.4-fold respectively).

The most interesting results were obtained in PTC group, where the $P R D X 1$ expression was reduced with statistical significance $(\mathrm{P}<0.05)$ compared to normal tissue $(14$-fold) and FA (26-fold). The strong reduction was evident also comparing PTCs to non-neoplastic tissue MNG (16-fold) and to FC (18-fold) (Fig. 1A). PRDX6 expression showed similar behavior, with a statistically significant $(\mathrm{P}<0.05)$ reduction, compared to contralateral normal tissue, and consistent reduction with respect to MNG (12-fold) and to follicular neoplasms (9- and 5-fold respectively) (Fig. 1A). The formalin-fixed, paraffin-embedded 

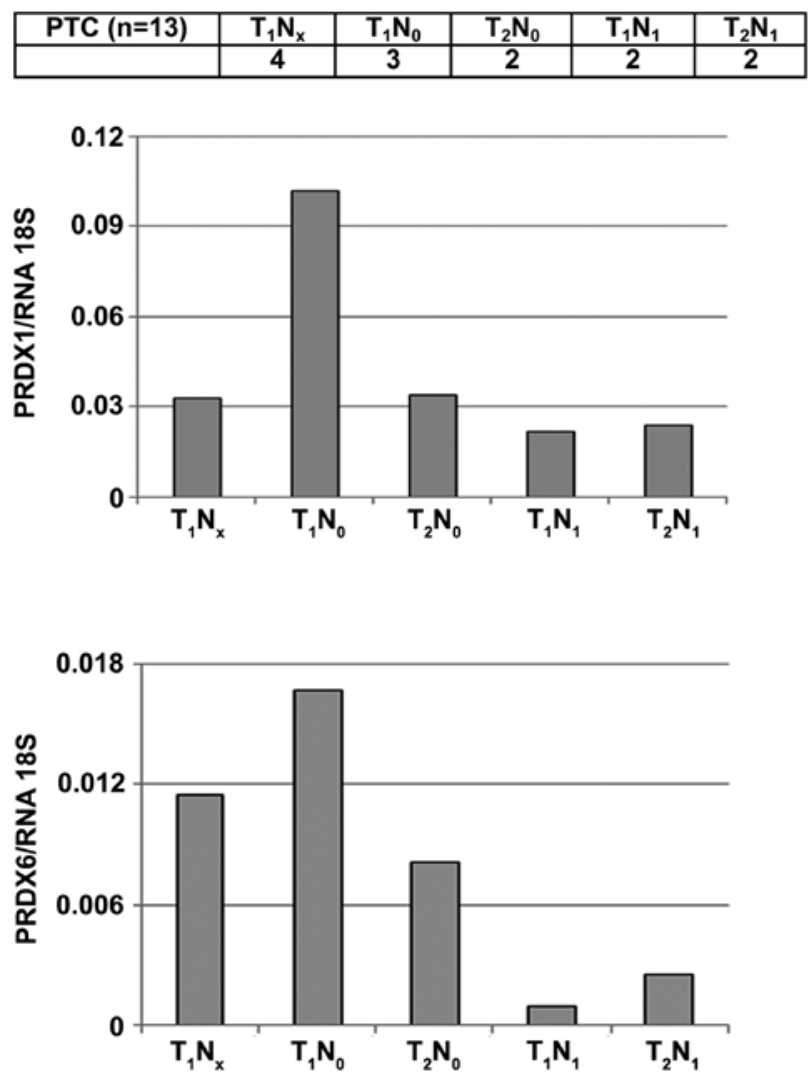

Figure 2. Correlation between PRDX1 and PRDX6 mRNA levels and TNM classification in PTCs. cases of the same PTC were studied by immunohistochemistry, using specific antibodies against PRDX1 and PRDX6. As shown in Fig. 1B, a weak intensity of PRDX1 and PRDX6 staining was present in all PTCs compared to non-neoplastic thyroid, substantially confirming the PCR (qRT-PCR) data. Tissues from thyroid Graves' disease were used as positive control (Fig. 1C).

Given the above findings, our study focused on the PTC group. In order to verify the possible correlation between PRDXs reduction and clinical behavior of PTC, we analyzed the data according to the TNM classification. As shown in Fig. 2 the lower levels of PRDXs were detected in PTC at stage $\mathrm{T}_{1} \mathrm{~N}_{1}$ (5-fold less than in $\mathrm{T}_{1} \mathrm{~N}_{0}$ ) and $\mathrm{T}_{2} \mathrm{~N}_{1}$ ( 2-fold less than in $\mathrm{T}_{2} \mathrm{~N}_{0}$ ) for PRDX1. We observed a similar trend towards $P R D X 6$, the reduction was 18-fold in $\mathrm{T}_{1} \mathrm{~N}_{1}$ vs $\mathrm{T}_{1} \mathrm{~N}_{0}$ and 3 -fold in $\mathrm{T}_{2} \mathrm{~N}_{1}$ compared to $\mathrm{T}_{2} \mathrm{~N}_{0}$ groups. Finally, these analyses also suggested that PRDX reduction could correlate with the tumor size, $\mathrm{T}_{2} \mathrm{~N}_{0}$ $\sim 3$ - and 2-fold less than $\mathrm{T}_{1} \mathrm{~N}_{0}$, respectively for $P R D X 1$ and PRDX6 (Fig. 2).

PRDX1 and PRDX6 expression level correlates with BRAF status and with nodal metastases. According to the literature (31), the sequencing of BRAF exon 15, performed in all PTC samples and in contralateral healthy tissue, demonstrated that BRAF V600E mutation was present in $31 \%$ (4 out of 13) of tumors. In our data, the $P R D X 1$ and $P R D X 6$ reduction was strongly pronounced (about 4- and 3-fold, respectively) in all BRAF V600E mutated with respect to non-mutated samples (Fig. 3A). These results were also confirmed by immunohis-
A
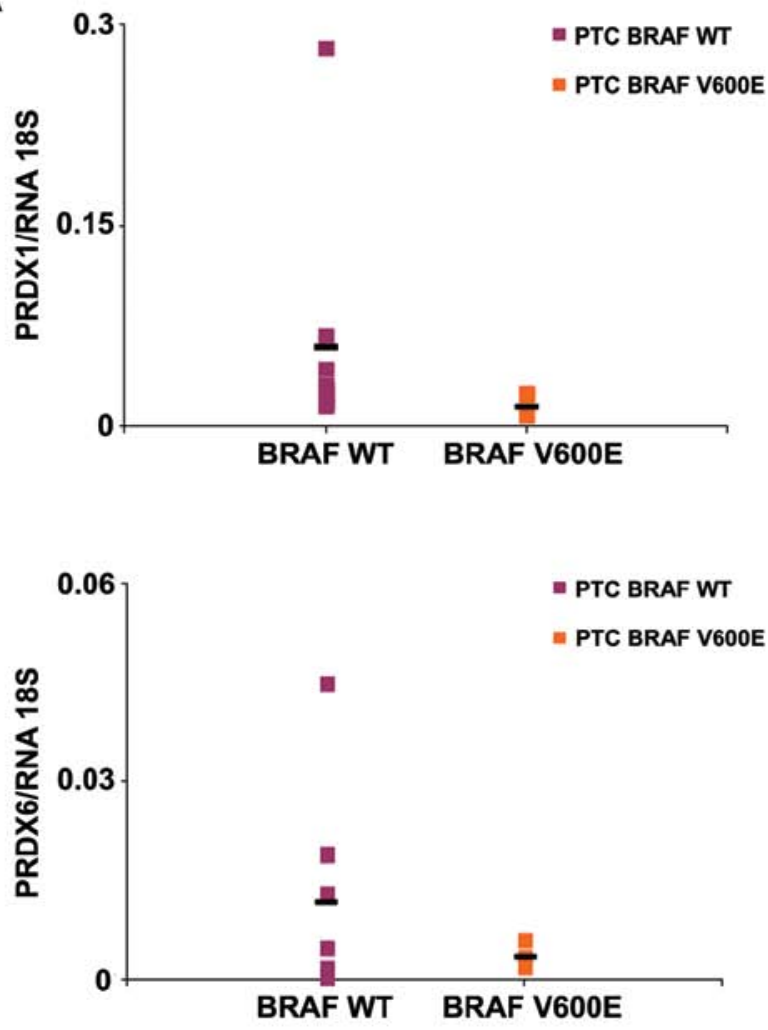

B

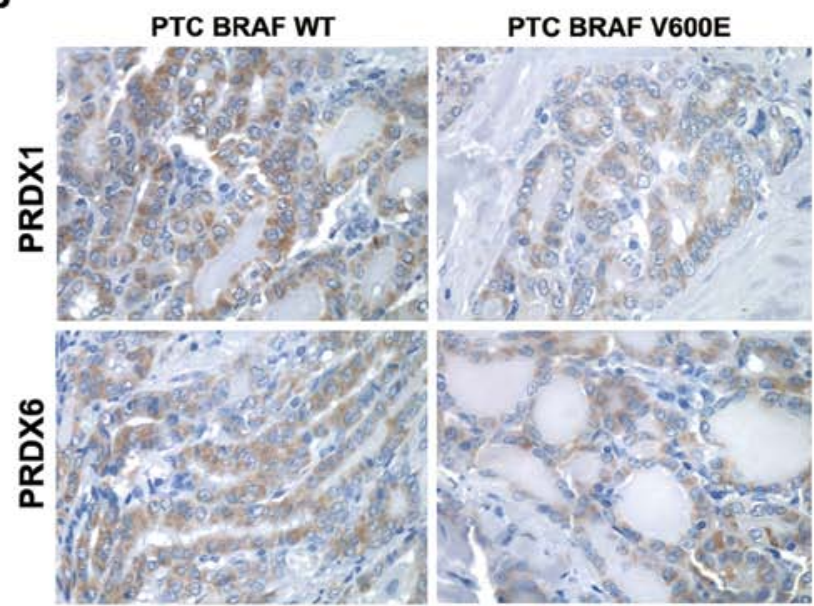

Figure 3. Correlation between PRDX1 and PRDX6 levels and BRAF status in PTC. (A) Relative gene expression levels of PRDX1 and PRDX6 normalized to 18S RNA in PTCs WT or PTCs BRAF V600E mutated. Values represent mean of triplicate determination \pm SD of three experiments. (B) Representative PRDX1 and PRDX6 immunohistochemistry (original magnification, x400) of PTCs WT (left) and BRAF V600E mutated (right). The evaluation of the two pathologists was $100 \%$ concordant. 


\begin{tabular}{|c|c|c|c|c|}
\hline PTC (n=9) & $\mathbf{T}_{1} \mathbf{N}_{0}$ & $\mathbf{T}_{2} \mathbf{N}_{0}$ & $\mathbf{T}_{1} \mathbf{N}_{1}$ & $\mathbf{T}_{2} \mathbf{N}_{1}$ \\
\hline BRAF WT & 2 & 1 & 2 & 2 \\
\hline BRAF V600E & 1 & 1 & - & - \\
\hline
\end{tabular}
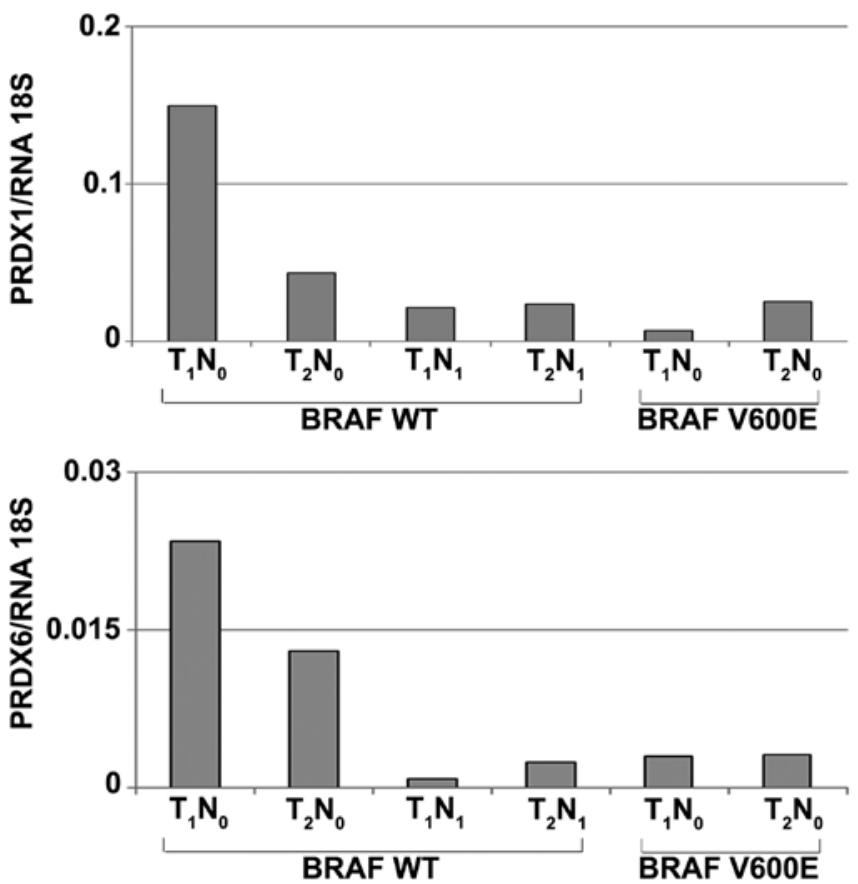

Figure 4. Correlation of PRDX1 and PRDX6 mRNA levels, TNM and BRAF status (described in the top table) in PTCs.

tochemistry, comparing the immunostaining of PRDX1 or PRDX6 of BRAF V600E mutated to non-mutated formalinfixed, paraffin-embedded samples (Fig. 3B).

Since we observed that the presence of nodal metastases correlated to the lowest PRDX levels (Fig. 2), we investigated whether the reduction could be dependent or independent by the BRAF status. We analyzed the PTC data, considering the subgroups according to the presence of BRAF V600E mutation and TNM. Interestingly, by means of this analyses we observed that, independently of BRAF status, the presence of nodal metastases correlated to the reduction of $P R D X 1$, about 7 times in $\mathrm{T}_{1} \mathrm{~N}_{1}$ vs $\mathrm{T}_{1} \mathrm{~N}_{0}$ and about 2 times in $\mathrm{T}_{2} \mathrm{~N}_{1}$ vs $\mathrm{T}_{2} \mathrm{~N}_{0}$, as well as of PRDX6, about 12 times in $\mathrm{T}_{1} \mathrm{~N}_{1}$ vs $\mathrm{T}_{1} \mathrm{~N}_{0}$ and about 5 times in $\mathrm{T}_{2} \mathrm{~N}_{1}$ vs $\mathrm{T}_{2} \mathrm{~N}_{0}$ (Fig. 4).

PRDX1 and PRDX6 are targets of BRAF V600E. To demonstrate that BRAF V600E might act as a repressor of PRDXs expression in PTCs, we used TPC-1 and BCPAP cells. These cell lines represent a model of human papillary thyroid carcinomas characterized, respectively, by the presence of the RET/PTC rearrangement and BRAF V600E mutation (36,39). TPC-1 and BCPAP were analyzed by qRT-PCR and western blot analysis. The data shown in Fig. 5A, clearly demonstrated that PRDX1 and PRDX6 transcripts were strongly reduced in BCPAP compared to TPC-1. Such a reduction was 31-fold $(\mathrm{P}<0.001)$ for PRDX1 and 22-fold $(\mathrm{P}<0.05)$ for PRDX6, respectively. Western blot analysis performed on total lysates of TPC-1 and BCPAP, further confirmed the strong and statistically significant reduction of PRDX1 and PRDX6 proteins in cells harboring BRAF V600E mutation (Fig. 5B). Thus, to test whether PRDX1 and PRDX6 were targets of BRAF V600E mutation, transient
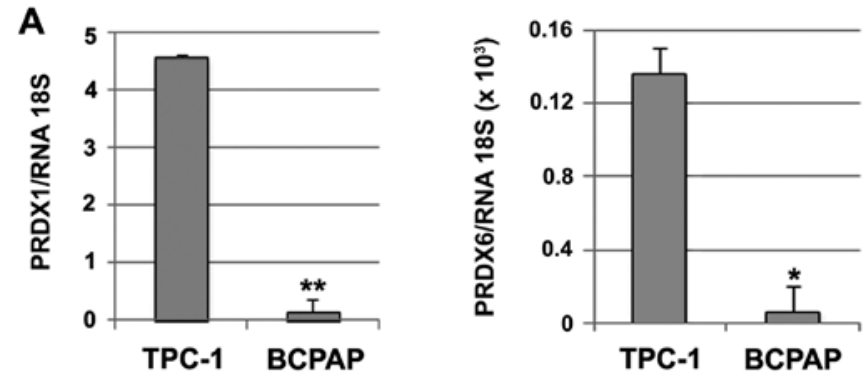

\section{B}
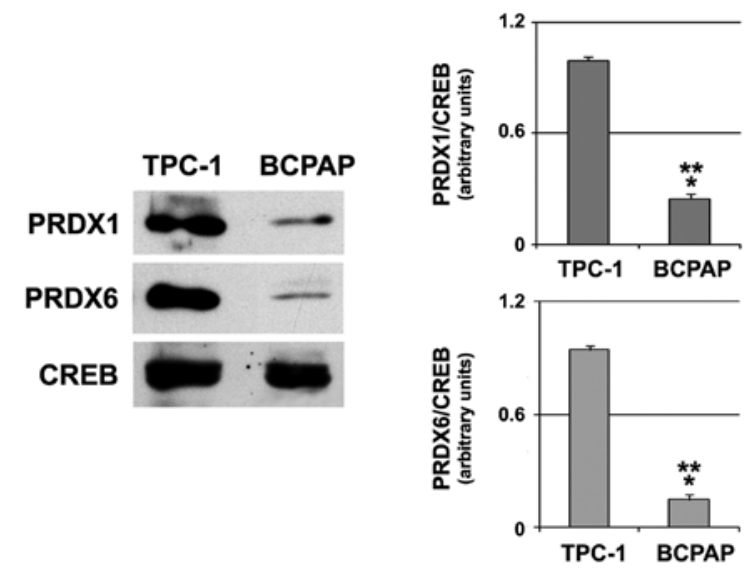

Figure 5. PRDX1 and PRDX6 expression in human PTC cell lines, TPC-1 and BCPAP. (A) Relative gene expression levels of PRDX1 and PRDX6, normalized to 18S RNA, in TPC-1 (BRAF WT/WT) and BCPAP (BRAF V600E/V600E). Values represent mean of triplicate determination \pm SD of three experiments. *Statistical significance (Student's t-test, $\mathrm{P}<0.05) ;{ }^{* *}$ High statistical significance (Student's t-test, $\mathrm{P}<0.001$ ) of BCPAP vs TPC-1. (B) Whole protein lysates (50 $\mu \mathrm{g}$ /lane) from TPC-1 and BCPAP were analyzed by western blot analysis using specific antibodies for PRDX1 or PRDX6. Densitometric evaluation of the PRDX1 or PRDX6 signals was performed normalizing to the levels of CREB. ${ }^{* * * *}$ Very high statistical significance (Student's t-test, $\left.\mathrm{P}<0.0001\right)$ of BCPAP vs TPC-1.

transfections of expression vector pBABE BRAF V600E were performed in FRTL-5. The expression of PRDXs, evaluated by qRT-PCR, revealed a statistically significant $(\mathrm{P}<0.05)$ reduction of both PRDX1 and PRDX6 in BRAF V600E transfected cells compared to untransfected (Fig. 6A). Similarly, western blot analysis performed on total lysates of FRTL-5 and FRTL-5 BRAF V600E, confirmed the statistically significant $(\mathrm{P}<0.05)$ decrease of both PRDXs in transfected cells (Fig. 6B).

\section{Discussion}

The thyroid cells are protected from reactive oxygen species (ROS), by means of catalase, glutathione peroxidase and peroxiredoxines production (40). TSH induces PRDX2 expression in FRTL-5 cells, indicating that the increase of the peroxidasemediated protection is required during TSH-dependent hormogenesis (5). Low iodine content diets may stimulate the expression of PRDX3 and PRDX5 (41); moreover, an increase of PRDX5 was found in Basedow (42). It seems that the increase of ROS, as a consequence of imbalanced intracellular redox systems, is an important event in thyroid cancerogenesis $(2,43)$. A recent study of oxidative status, performed on serum of patients with thyroid cancer, demonstrates an increase of oxidants and a decrease of antioxidants (44), especially evident in papillary thyroid carcinomas (3). Therefore, the alteration in 

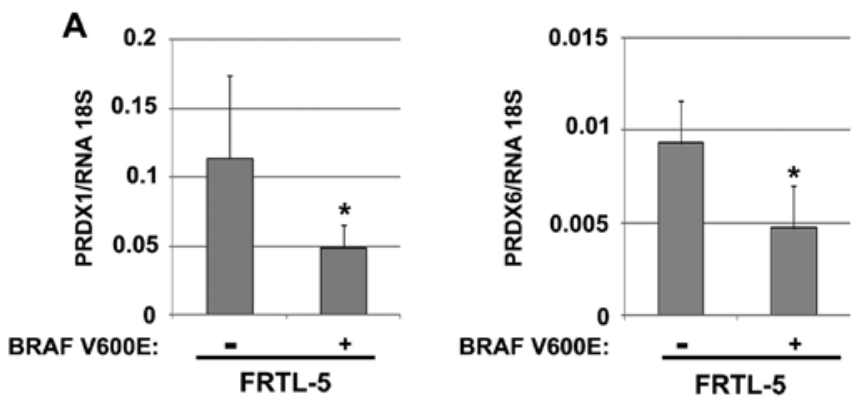

B

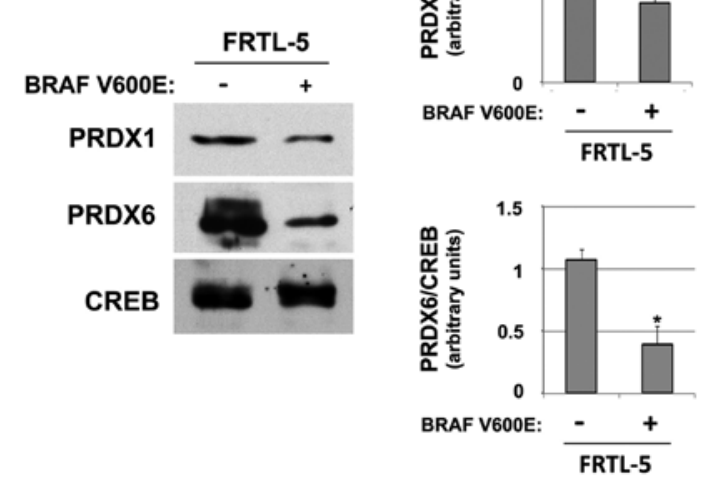

Figure 6. Effect of BRAF V600E transfection on PRDX1 and PRDX6 expression in FRTL-5 cells. (A) The expression of PRDX1 and PRDX6 was evaluated by qRT-PCR analysis on mRNA obtained from FRTL-5 untransfected or transiently transfected with pBABE BRAF V600E plasmid. Relative gene expression levels were normalized to $18 \mathrm{~S}$ RNA. *Statistical significance (Student's t-test, $\mathrm{P}<0.05$ ) of FRTL-5 transfected vs untransfected cells. (B) Whole protein lysates (50 $\mu \mathrm{g} / \mathrm{lane})$ from FRTL-5 transfected or not with pBABE BRAF V600E plasmid were analyzed by western blot analysis using an antibody against PRDX1 or PRDX6. Densitometric evaluation of the PRDX signals was performed normalizing to the levels of CREB. "Statistical significance (Student's t-test, $\mathrm{P}<0.05$ ) of FRTL-5 transfected vs untransfected cells.

peroxidase-mediated protection could represent an important mechanism involved in the pathogenesis of several thyroid diseases, including cancer.

According to this premise, in this study we demonstrate that, in all PTCs examined, the levels of PRDX1 and PRDX6 are significantly reduced compared to normal tissue, thus confirming the importance that the PRDXs play in protecting the thyroid cells from the negative effect of the OS. On the other hand, different mechanisms could be implicated in follicular neoplasms particularly FA, where we found increased levels of PRDX1, according to Yanagawa et al (24) and underexpression of PRDX6 according to Sofiadis et al (25). These observations strongly support the idea that the role of PRDXs in thyroid cancer needs to be further clarified.

The recent progress in understanding the molecular pathogenesis of thyroid cancer has shown great promise for the development of more effective treatment strategies. Several genetic alterations with a fundamental role in the tumorigenesis of various thyroid tumors have been identified. An important example is represented by the T1799A transverse point mutation of BRAF, which results in the expression of BRAF V600E mutant protein, responsible of a constitutive activation of this serine/threonine kinase. This mutation occurs in approximately
$45 \%$ of PTCs and it is strongly associated with a poor clinic pathological outcome of PTC, including aggressive pathological features, increased recurrence, loss of radioiodine avidity and treatment failures $(32,45-48)$. In agreement with these reports, we found BRAF V600E mutation in $31 \%$ of PTC. All mutated samples, compared to WT, show a strong reduction of PRDX1 and PRDX6 expression levels, both at mRNA and protein level. To date, a specific mechanism governing the modulation of PRDXs in human cancer has not yet been described; instead, several molecular modifications have been observed associated to BRAF mutation, including the mutation-promoted overexpression of tumor-promoting molecules $(49,50)$, suppression of tumor-suppressor genes $(51,52)$, and silencing of iodide-handling genes with impaired radioiodine avidity in PTC $(53,54)$. In our study, we demonstrate for the first time, that the presence of BRAF V600E in thyroid cells correlates with a reduction of PRDX1 and PRDX6 levels. BCPAP cell line, which presents BRAF V600E mutation, shows a statistically significant reduction of PRDXs mRNA and proteins compared to TPC-1 cell, characterized by the presence of RET/PTC rearrangement. When BRAF V600E is expressed in FRTL-5 cells, mRNA and protein expression of PRDX1 and PRDX6 is strongly reduced. These findings let us conclude that PRDXs represent another important target of BRAF V600E mutation, that could contribute to more aggressive clinical outcome of carcinoma, reducing the protection from oxidative stress.

Many clinical studies highlight the dichotomous role of PRDX members, depending on the tumor type and on the stage of tumor progression. Lower expression of PRDX2 correlates in CRC with advanced clinical stage, poorer tumor differentiation, distant metastasis and poor survival (55). PRDX1 appears to be upregulated in lung tumors (56), while it is downregulated in esophageal squamous carcinomas, where its reduction correlates with a cancer progression (18). Interestingly, we observed that the strong reduction of PRDXs correlates also with lymph node metastasis. Independently of BRAF status, lower levels of PRDXI and PRDX6 are observable in PTC at stage $\mathrm{T}_{1} \mathrm{~N}_{1}$ and $\mathrm{T}_{2} \mathrm{~N}_{1}$. Thus, these preliminary data suggest that the determination of PRDX1 and PRDX6 could be of relevance for monitoring PTC clinical behavior.

In conclusion, our study demonstrates that the PRDXs reduction is a feature of PTCs. Their expression is strongly modulated by BRAF V600E, as shown in human PTCs and in cellular model. PRDX1 and PRDX6 reduction correlates with the stage of the diseases, independently of BRAF status. Our findings provide strong evidence that PRDX1 and PRDX6 are targets of BRAF V600E and that their reduction in PTCs contributes to more aggressive clinical outcome of PTCs, reducing the protection from oxidative stress. Finally, although based on a small number of cases, we think PRDXs could be considered as potential tumor markers for indicating tumor progression and lymph nodal metastases in PTCs.

\section{Acknowledgements}

We thank Dr Graziano De Luca (Unit of Pathology and Molecular Medicine, Department of Medicine and Science of Aging, Hospital 'SS. Annunziata' Chieti) and Dr Chiara Tarantelli, for collection, storage and management of Biobank samples. The authors would also like to thank Mr. Daniel Kenton for the 
careful revisions made. This work was partially supported by grants from ASI-Italian Space Agency (I/003/11/0).

\section{References}

1. Senthil N and Manoharan S: Lipid peroxidation and antioxidants status in patients with papillary thyroid carcinoma in India. Asia Pac J Clin Nutr 13: 391-395, 2004.

2. Akinci M, Kosova F, Cetin B, Sepici A, Altan N, Aslan S and Cetin A: Oxidant/antioxidant balance in patients with thyroid cancer. Acta Cir Bras 23: 551-554, 2008.

3. Lassoued S, Mseddi M,Mnif F, Abid M, Guermazi F, Masmoudi H, El Feki A and Attia H: A comparative study of the oxidative profile in Graves' disease, Hashimoto's thyroiditis, and papillary thyroid cancer. Biol Trace Elem Res 138: 107-115, 2010.

4. De Deken X, Wang D, Dumont JE and Miot F: Characterization of ThOX proteins as components of the thyroid $\mathrm{H}(2) \mathrm{O}(2)$-generating system. Exp Cell Res 273: 187-196, 2002.

5. Schweizer U, Chiu J and Köhrle J: Peroxides and peroxidedegrading enzymes in the thyroid. Antioxid Redox Signal 10 1577-1592, 2008.

6. Edgar RS, Green EW, Zhao Y, van Ooijen G, Olmedo M, Qin X, Xu Y, Pan M, Valekunja UK, Feeney KA, Maywood ES, Hastings MH, Baliga NS, Merrow M, Millar AJ, Johnson CH, Kyriacou CP, O'Neill JS and Reddy AB: Peroxiredoxins are conserved markers of circadian rhythms. Nature 485: 459-464 2012.

7. Turner-Ivey B, Manevich Y, Schulte J, Kistner-Griffin E, JezierskaDrutel A, Liu Y and Neumann CA: Role for Prdx1 as a specific sensor in redox-regulated senescence in breast cancer. Oncogene doi: 10.1038/onc.2012.624, 2013 [Epub ahead of print]

8. Manevich Y and Fisher AB: Peroxiredoxin 6, a 1-Cys peroxiredoxin, functions in antioxidant defense and lung phospholipid metabolism. Free Radic Biol Med 38: 1422-1432, 2005.

9. Hofmann B, Hecht HJ and Flohé L: Peroxiredoxins. Biol Chem 383: 347-364, 2002

10. Wood ZA, Schröder E, Robin Harris J and Poole LB: Structure, mechanism and regulation of peroxiredoxins. Trends Biochem Sci 28: 32-40, 2003

11. Neumann CA, Krause DS, Carman CV, Das S, Dubey DP, Abraham JL, Bronson RT, Fujiwara Y, Orkin SH and van Etten RA: Essential role for the peroxiredoxin Prdx1 in erythrocyte antioxidant defence and tumour suppression. Nature 424 561-565, 2003

12. Egler RA, Fernandes E, Rothermund K, Sereika S, De SouzaPinto N, Jaruga P, Dizdaroglu M and Prochownik EV: Regulation of reactive oxygen species, DNA damage, and c-Myc function by peroxiredoxin 1. Oncogene 24: 8038-8050, 2005.

13. Neumann CA and Fang Q: Are peroxiredoxins tumor suppressors? Curr Opin Pharmacol 7: 375-380, 2007.

14. Lehtonen ST, Svensk AM, Soini Y, Pääkkö P, Hirvikoski P Kang SW, Säily M and Kinnula VL: Peroxiredoxins, a nove protein family in lung cancer. Int J Cancer 111: 514-521, 2004.

15. Park JH, Kim YS, Lee HL, Shim JY, Lee KS, Oh YJ, Shin SS, Choi YH, Park KJ, Park RW and Hwang SC: Expression of peroxiredoxin and thioredoxin in human lung cancer and paired normal lung. Respirology 11: 269-275, 2006.

16. Kim JH, Bogner PN, Baek SH, Ramnath N, Liang P, Kim HR, Andrews $\mathrm{C}$ and Park YM: Up-regulation of peroxiredoxin 1 in lung cancer and its implication as a prognostic and therapeutic target. Clin Cancer Res 14: 2326-2333, 2008.

17. Goncalves K, Sullivan K and Phelan S: Differential expression and function of peroxiredoxin 1 and peroxiredoxin 6 in cancerous MCF-7 and noncancerous MCF-10A breast epithelial cells. Cancer Invest 30: 38-47, 2012.

18. Hoshino I, Matsubara H, Akutsu Y, Nishimori T, Yoneyama Y, Murakami K, Sakata H, Matsushita K and Ochiai T: Tumor suppressor Prdx 1 is a prognostic factor in esophageal squamous cell carcinoma patients. Oncol Rep 18: 867-871, 2007.

19. Kinnula VL, Lehtonen S, Sormunen R, Kaarteenaho-Wiik R, Kang SW, Rhee SG and Soini Y: Overexpression of peroxiredoxins I, II, III, V, and VI in malignant mesothelioma. J Pathol 196: 316-323, 2002.

20. Fujita Y, Nakanishi T, Hiramatsu M, Mabuchi H, Miyamoto Y, Miyamoto A, Shimizu A and Tanigawa N: Proteomics-based approach identifying autoantibody against peroxiredoxin VI as a novel serum marker in esophageal squamous cell carcinoma. Clin Cancer Res 12: 6415-6420, 2006.
21. Park CK, Kim JH, Moon MJ, Jung JH, Lim SY, Park SH, Kim DG, Jung HW, Cho BK and Paek SH: Investigation of molecular factors associated with malignant transformation of oligodendroglioma by proteomic study of a single case of rapid tumor progression. J Cancer Res Clin Oncol 134: 255-262, 2008

22. Karihtala P, Mantyniemi A, Kang SW, Kinnula VL and Soini Y: Peroxiredoxins in breast carcinoma. Clin Cancer Res 9: 3418-3424, 2003.

23. Rolfs F, Huber M, Gruber F, Böhm F, Pfister HJ, Bochkov VN, Tschachler E, Dummer R, Hohl D, Schäfer M and Werner S: Dual role of the antioxidant enzyme peroxiredoxin 6 in skin carcinogenesis. Cancer Res 73: 3460-3469, 2013.

24. Yanagawa T, Ishikawa T, Ishii T, Tabuchi K, Iwasa S, Bannai S, Omura K, Suzuki H and Yoshida H: Peroxiredoxin I expression in human thyroid tumors. Cancer Lett 145: 127-132, 1999.

25. Sofiadis A, Becker S, Hellman U, Hultin-Rosenberg L, Dinets A, Hulchiy M, Zedenius J, Wallin G, Foukakis T, Höög A, Auer G, Lehtiö J and Larsson C: Proteomic profiling of follicular and papillary thyroid tumors. Eur J Endocrinol 166: 657-667, 2012.

26. Leenhardt L, Grosclaude P and Chérié-Challine L: Thyroid Cancer Committee. Increased incidence of thyroid carcinoma in France: a true epidemic or thyroid nodule management effects? Report from the French Thyroid Cancer Committee. Thyroid 14: 1056-1060, 2004

27. Davies L and Welch HG: Increasing incidence of thyroid cancer in the United States, 1973-2002. JAMA 295: 2164-2167, 2006.

28. Mazzaferri EL: Management of low-risk differentiated thyroid cancer. Endocr Pract 13: 498-512, 2007.

29. Roti E,Degli Uberti EC, Bondanelli M and Braverman LE: Thyroid papillary microcarcinoma: a descriptive and meta-analysis study. Eur J Endocrinol 159: 659-673, 2008.

30. Nikiforova MN, Kimura ET, Gandhi M, Biddinger PW, Knauf JA, Basolo F, Zhu Z, Giannini R, Salvatore G, Fusco A, Santoro M, Fagin JA and Nikiforov YE: BRAF mutations in thyroid tumors are restricted to papillary carcinomas and anaplastic or poorly differentiated carcinomas arising from papillary carcinomas. J Clin Endocrinol Metab 88: 5399-5404, 2003.

31. Xing M: Prognostic utility of BRAF mutation in papillary thyroid cancer. Mol Cell Endocrinol 321: 86-93, 2010.

32. Xing M: Molecular pathogenesis and mechanisms of thyroid cancer. Nat Rev Cancer 13: 184-199, 2013.

33. Lazzereschi D, Ranieri A, Mincione G, Taccogna S, Nardi F and Colletta G: Human malignant thyroid tumors displayed reduced levels of transforming growth factor beta receptor type II messenger RNA and protein. Cancer Res 57: 2071-2076, 1997.

34. Ambesi-Impiombato FS, Parks LA and Coon HG: Culture of hormone-dependent functional epithelial cells from rat thyroids. Proc Natl Acad Sci USA 77: 3455-3459, 1980.

35. D'Inzeo S, Nicolussi A, Donini CF, Zani M, Mancini P, Nardi F and Coppa A: A novel human Smad4 mutation is involved in papillary thyroid carcinoma progression. Endocr Relat Cancer 19: 39-55, 2012.

36. Schweppe RE, Klopper JP, Korch C, Pugazhenthi U, Benezra M, Knauf JA, Fagin JA, Marlow LA, Copland JA, Smallridge RC and Haugen BR: Deoxyribonucleic acid profiling analysis of 40 human thyroid cancer cell lines reveals cross-contamination resulting in cell line redundancy and misidentification. J Clin Endocrinol Metab 93: 4331-4341, 2008.

37. D'Inzeo S, Nicolussi A, Ricci A, Mancini P, Porcellini A, Nardi F and Coppa A: Role of reduced expression of SMAD4 in papillary thyroid carcinoma. J Mol Endocrinol 45: 229-244, 2010.

38. Nicolussi A, D'Inzeo S, Gismondi A and Coppa A: Reduction of invasive potential in K-ras-transformed thyroid cells by restoring of TGF-beta pathway. Clin Exp Metastasis 23: 237-248, 2006.

39. Meireles AM, Preto A, Rocha AS, Rebocho AP, Máximo V, Pereira-Castro I, Moreira S, Feijão T, Botelho T, Marques R, Trovisco V, Cirnes L, Alves C, Velho S, Soares P and SobrinhoSimões M: Molecular and genotypic characterization of human thyroid follicular cell carcinoma-derived cell lines. Thyroid 17: 707-715, 2007.

40. Poncin S, Colin IM and Gérard AC: Minimal oxidative load: a prerequisite for thyroid cell function. J Endocrinol 201: 161-167, 2009.

41. Maier J, van Steeg H, van Oostrom C, Paschke R, Weiss RE and Krohn K: Iodine deficiency activates antioxidant genes and causes DNA damage in the thyroid gland of rats and mice. Biochim Biophys Acta 1773: 990-999, 2007.

42. Gérard AC, Many MC, Daumerie Ch, Knoops B and Colin IM: Peroxiredoxin 5 expression in the human thyroid gland. Thyroid 15: 205-209, 2005 
43. Xing M: Oxidative stress: a new risk factor for thyroid cancer Endocr Relat Cancer 19: C7-C11, 2012.

44. Wang D, Feng JF, Zeng P, Yang YH, Luo J and Yang YW: Total oxidant/antioxidant status in sera of patients with thyroid cancers. Endocr Relat Cancer 18: 773-782, 2011.

45. Cohen Y, Xing M, Mambo E, Guo Z, Wu G, Trink B, Beller U, Westra WH, Ladenson PW and Sidransky D: BRAF mutation in papillary thyroid carcinoma. J Natl Cancer Inst 95: 625-627, 2003.

46. Fukushima T, Suzuki S, Mashiko M, Ohtake T, Endo Y, Takebayashi Y, Sekikawa K, Hagiwara K and Takenoshita S: BRAF mutations in papillary carcinomas of the thyroid. Oncogene 22: 6455-6457, 2003.

47. Kimura ET, Nikiforova MN, Zhu Z, Knauf JA, Nikiforov YE and Fagin JA: High prevalence of BRAF mutations in thyroid cancer: genetic evidence for constitutive activation of the RET/PTC-RASBRAF signaling pathway in papillary thyroid carcinoma. Cancer Res 63: 1454-1457, 2003.

48. Xu X, Quiros RM, Gattuso P, Ain KB and Prinz RA: High prevalence of BRAF gene mutation in papillary thyroid carcinomas and thyroid tumor cell lines. Cancer Res 63: 4561-4567, 2003.

49. Frasca F, Nucera C, Pellegriti G, Gangemi P, Attard M, Stella M, Loda M, Vella V, Giordano C, Trimarchi F, Mazzon E, Belfiore A and Vigneri R: BRAF (V600E) mutation and the biology of papillary thyroid cancer. Endocr Relat Cancer 15: 191-205, 2008.

50. Watanabe R, Hayashi Y, Sassa M, Kikumori T, Imai T, Kiuchi T and Murata Y: Possible involvement of BRAFV600E in altered gene expression in papillary thyroid cancer. Endocr J 56: 407-414, 2009.
51. Hu S, Liu D, Tufano RP, Carson KA, Rosenbaum E, Cohen Y, Holt EH, Kiseljak-Vassiliades K, Rhoden KJ, Tolaney S, Condouris S, Tallini G, Westra WH, Umbricht CB, Zeiger MA, Califano JA, Vasko V and Xing M: Association of aberrant methylation of tumor suppressor genes with tumor aggressiveness and BRAF mutation in papillary thyroid cancer. Int J Cancer 119: 2322-2329, 2006

52. Guan H, Ji M, Hou P, Liu Z, Wang C, Shan Z, Teng W and Xing M: Hypermethylation of the DNA mismatch repair gene hMLH1 and its association with lymph node metastasis and T1799A BRAF mutation in patients with papillary thyroid cancer. Cancer 113: 247-255, 2008.

53. Riesco-Eizaguirre G, Rodríguez I, De la Vieja A, Costamagna E Carrasco N, Nistal M and Santisteban P: The BRAFV600E oncogene induces transforming growth factor beta secretion leading to sodium iodide symporter repression and increased malignancy in thyroid cancer. Cancer Res 69: 8317-8325, 2009.

54. Knauf JA, Sartor MA, Medvedovic M, Lundsmith E, Ryder M, Salzano M, Nikiforov YE, Giordano TJ, Ghossein RA and Fagin JA: Progression of BRAF-induced thyroid cancer is associated with epithelial-mesenchymal transition requiring concomitant MAP kinase and TGF $\beta$ signaling. Oncogene 30: 3153-3162, 2011

55. Ji D, Li M, Zhan T, Yao Y, Shen J, Tian H, Zhang Z and Gu J: Prognostic role of serum AZGP1, PEDF and PRDX 2 in colorectal cancer patients. Carcinogenesis 34: 1265-1272, 2013.

56. Park YH, Kim SU, Lee BK, Kim HS, Song IS, Shin HJ, Han YH, Chang KT, Kim JM, Lee DS, Kim YH, Choi CM, Kim BY and Yu DY: Prx I suppresses K-ras-driven lung tumorigenesis by opposing redox-sensitive ERK/cyclin D1 pathway. Antioxid Redox Signal 19: 482-496, 2013. 